\title{
El derecho a la ciudad: de Henri Lefebvre a los análisis sobre la ciudad capitalista contemporánea ${ }^{1}$
}

\author{
The Right to the City: From Henri Lefebvre to the Analysis about the \\ Contemporary Capitalist City
}

O direito à cidade: de Henri Lefevbre aos análises sobre a cidade
capitalista contemporânea

Frank Molano Camargo ${ }^{2}$

\section{Resumen}

El derecho a la ciudad, definido por Henri Lefebvre en 1967 como el derecho de los habitantes urbanos a construir, decidir y crear la ciudad, $y$ hacer de esta un espacio privilegiado de lucha anticapitalista, se encuentra de nuevo en el centro del debate político. Investigadores sociales, movimientos sociales, agencias de cooperación internacional y Estados lo asumen como referente de análisis y postura política para discutir sobre los cambios urbanos de las ciudades capitalistas contemporáneas. Este artículo analiza los supuestos planteados por Lefebvre en 1967 y la transformación que el concepto de derecho a la ciudad ha tenido a partir de autores como David Harvey, Edward Soja y Ana Fani Alessandri Carlos.

Palabras clave: Derecho a la ciudad, producción del espacio, urbanismo capitalista, alternativas espaciales

\section{Abstract}

The right to the city, defined by Henri Lefebvre in 1967 as the right of urban inhabitants to build, decide and create the city, and make of it a privileged space of anti-capitalist struggle, is again at the center of political debate. Social scientists, social movements, international aid agencies and States take it as a benchmark for policy analysis and to discuss the urban changes in contemporary capitalist cities. This article discusses the assumptions made by Lefebvre in 1967 and the transformation that the concept of right to the city has had from authors such as David Harvey, Edward Soja and Ana Fani Alessandri Carlos.

Keywords: Rigth to the city, production of space, capitalist urbanism, space alternatives

Resumo

0 direito à cidade, definido por Henri Lefebvre em 1967 como o direito dos moradores urbanos para construir, decidir e crear a cidade, e fazer desta um espaço privilegiado de luta anticapitalista, encontra-se de novo no centro do debate publico. Pesquisadores sociais, movimentos sociais, agências de cooperação internacional e Estados consideram isso como um referente de analisis e orientação política para debater sobre as mudanças urbanas das cidades capitalistas contemporâneas. Este artigo examina as premissas feitas por Lefebvre em 1967 e a transformação que o conceito de direito à cidade há tido a partir de autores como David Harvey, Edward Soja y Ana Fani Alessandri Carlos.

Palavras chave: Direito à cidade, produção do espaço, urbanismo capitalista, alternativas espaciais

Artículo recibido el 28 de mayo de 2015 y aprobado el 27 de enero de 2016

1 El escrito se inscribe en el proyecto de investigación doctoral titulado La guerra contra la basura. Conflictos socio-ambientales en Bogotá 1950-2000, adelantado en el Doctorado de Historia en la Universidad de Los Andes, Bogotá, Colombia.

2 Universidad Distrital Francisco José de Caldas. Bogotá, Colombia. Doctorado en Historia de la Universidad de Los Andes, Bogotá, Colombia. Correo electrónico: f.molano10@uniandes.edu.co 
Universidad Pedagógica Nacional

Facultad de Humanidades

\section{Introducción}

El derecho a la ciudad, definido por Henri Lefebvre en 1967 como el derecho de los habitantes urbanos a construir, decidir y crear la ciudad, y hacer de esta un espacio privilegiado de lucha anticapitalista, se encuentra de nuevo en el centro del debate político. Este resurgimiento se debe especialmente a la explosión de nuevas luchas urbanas contra las expresiones espaciales del dominio del capital financiero, como la gentrificación o la degradación ambiental, pero también, al esfuerzo de los habitantes por lograr una mayor injerencia en la definición de las políticas urbanas. El propósito de este ensayo es analizar la reapropiación contemporánea, en términos tanto teóricos como políticos, del derecho a la ciudad propuesto originalmente por Lefebvre. Se analizarán primero los ejes fundamentales del derecho a la ciudad planteados por Lefevbre, y luego las propuestas de tres autores: David Harvey, Edward Soja y Ana Fani Alessandri Carlos, que asumen el derecho a la ciudad, al igual que Lefebvre, como un marco de comprensión para el estudio de los problemas socioespaciales urbanos. En el ensayo se compararán los enfoques de cada autor, sus categorías claves, y las implicaciones y posibilidades de ejercicio del derecho a la ciudad planteadas por cada uno de ellos. Esta mirada, a partir de diferentes enfoques, sugiere además temas y problemas de investigación desde las ciencias sociales para el estudio de la ciudad.

Lefebvre planteó el derecho a la ciudad como una alternativa a la enajenación y a la despolitización que el urbanismo moderno, promovido en general por los Estados modernos, había producido en la sociedad. Hoy en día, sin embargo, quienes reivindican el concepto lo hacen discutiendo las posibilidades de la lucha anticapitalista urbana, y evidenciando que la mayor globalización económica, así como la subordinación del Estado al capital internacional, obligan en consecuencia a una relectura y actualización del planteamiento lefebvriano ${ }^{3}$.

3 Entre quienes hoy reivindican el derecho a la ciudad se encuentran la Coalición Internacional del Hábitat (Habitat International Coalition-HIC), que estableció en 2004 la Carta Mundial del Derecho a la Ciudad. El Foro Urbano Mundial de 2010, que tuvo como lema “El derecho a la ciudad: reduciendo lo urbano dividido o uniendo
A pesar de esta necesaria relectura, el derecho a la ciudad mantiene su vigencia precisamente porque la intervención urbana del capital financiero y la privatización de los servicios urbanos y del suelo urbano han profundizado aún más las contradicciones sociales urbanas que estudió Lefebvre. Hoy tenemos mayor crecimiento económico, expansión urbana y mejores condiciones tecnológicas para diseñar la ciudad, sin embargo los mecanismos de segregación espacial, el empobrecimiento de la experiencia urbana y la restricción de la participación y la democracia urbana dificultan el acceso a la ciudad a la mayoría de sus habitantes (Do Rio Caldeira, 2007). Además, como sostiene el urbanista estadounidense Mark Purcell (2007), quienes estudian la ciudad en clave del derecho a la ciudad, suponen que la reestructuración urbana impulsada por el capitalismo financiero y el modelo neoliberal, al tiempo que han llevado a la privatización de los servicios públicos urbanos, han limitado el acceso ciudadano a las decisiones sobre la ciudad.

El pensamiento de Lefebvre y su concepto de derecho a la ciudad han tenido una trayectoria zigzagueante. Durante la década de 1970 sus planteamientos se mantuvieron en un relativo olvido, por lo menos en el contexto anglosajón y en parte de América Latina, ante la preeminencia adquirida entonces por el análisis estructuralista sobre la cuestión urbana, propuesto entre otros por Manuel Castells y los teóricos de la dependencia ${ }^{4}$. El mismo Castells fue un duro crítico de Lefebvre, pues consideró que hablar de "sociedad urbana" y de "producción social del espacio", conceptos en los

lo urbano dividido"; en 2011 la revista española Urban editó un número titulado "Espectros de Lefebvre"; en 2012 la revista francesa L'Homme et la Sociéte, dedicó un número a Lefebvre; en Colombia, la revista Territorios 29 de la Universidad del Rosario, “La vigencia de Henri Lefebvre en la investigación socio-territorial"; en 2013 investigadores de Ecuador y Argentina dieron inicio al Grupo de Trabajo Clacso sobre el derecho a la ciudad en América Latina.

4 Andy Merrifield (2002), considera que el "ostracismo" a que fue sometida la obra de Lefebvre se debió a dos cuestiones: la crítica estructuralista que le realizó Manuel Castells y la enemistad con los intelectuales marxistas franceses por la posición ambigua que Lefebvre asumió hacia el mayo de 1968. No obstante en contextos como Brasil, la teoría de la dependencia no impidió a geógrafos como Milton Santos retomar las tesis de Lefebvre y ponerlas en diálogo con otros enfoques de análisis urbano. 
cuales la vida cotidiana y la subjetividad tenían un peso significativo, dejaban a un lado el estudio de la ideología dominante, de la base económica de la sociedad y de la lucha de clases (Castells, 1988). Una década después, sin embargo, los planteamientos de Lefebvre fueron retomados por la academia estadounidense. Según la geógrafa francesa Claire Revol-Buisson (2014), David Harvey constituyó la primera generación anglosajona de estudios lefebvrianos, cuyo énfasis fue el análisis económico marxista; Edward Soja representó la segunda generación que en la década de 1980 releyó a Lefebvre con los lentes del posmodernismo y los estudios culturales, lo que implicó el desplazamiento de la economía política por el análisis cultural de la ciudad con importantes implicaciones para la acción política (Revol-Buisson, 2014). Fue desde estas dos relecturas que, según esta autora, Lefebvre volvió al escenario de las ciencias sociales.

El interés por la teoría urbana en la perspectiva propuesta por Lefebvre y por el derecho a la ciudad ha supuesto nuevas oportunidades pero también nuevos riesgos. En lo político, el debate se ha centrado en las posibilidades y los peligros del ejercicio del derecho a la ciudad, teniendo en cuenta que éste ha sido retomado no solo por los movimientos sociales, sino también por organismos de cooperación internacional y por los Estados. Laurence Costes, socióloga urbana francesa, por ejemplo, considera que esta institucionalización del derecho a la ciudad es una oportunidad abierta por las luchas urbanas para crear espacios políticos y democratizar las decisiones (2014). Sin embargo, otros autores tienen una posición menos optimista. Andy Merrifield (2012), urbanista marxista y biógrafo de Lefebvre, por el contrario, ha propuesto sopesar la validez y utilidad política del concepto, ahora que ha sufrido una "reapropiación burguesa”. En la misma línea el geógrafo indo-canadiense Kanishka Goonewardena, considera que la institucionalización del derecho a la ciudad ha implicado la cooptación y despolitización del proyecto lefebvriano, ya que los gobiernos capitalistas y las oNG que interactúan en su marco, tienden a desconocer las implicaciones del análisis marxista sobre la ciudad y a colocar el derecho a la ciudad en una "cómoda posición liberal anglosajona" (2012).

Estas polémicas se dan además en un marco histórico en el que la expansión del capital financiero, la crisis económica global y las exigencias de democracia por parte de movimientos de protesta urbana, están obligando a los teóricos neoliberales que clamaron por el completo desmonte del Estado, a reconsiderar sus funciones de regulación, para hacer frente a la recurrencia de las crisis económicas. Un ejemplo es el de las teorías políticas neoinstitucionales que enfatizan en la alianza público-privada como medidas para establecer controles al mercado, que algunos autores denominan sociedad posneoliberal (Dávalos, 2011). Es importante precisar que el continuo pero fortalecido llamado al derecho a la ciudad a comienzos del siglo xxI, y particularmente luego de la crisis económica de 2008 que se inició como burbuja inmobiliaria en Estados Unidos, está asociado a las movilizaciones sociales y la exigencia de derechos ciudadanos, que llamó la atención de los académicos, que asumieron el enfoque del derecho a la ciudad para buscar explicaciones sobre cómo estaban respondiendo los habitantes urbanos ante el proceso de urbanización del capitalismo financiero y las políticas neoliberales y posneoliberales.

Para analizar las diferentes maneras en que el derecho a la ciudad ha sido propuesto y reinterpretado, el presente ensayo se organiza en cinco apartados. En primer lugar se describen los elementos centrales del derecho a la ciudad como construcción autónoma y obra colectiva frente al capital y al Estado, propuestos por Henri Lefebvre. En segundo lugar, se discute la manera en que David Harvey asume el derecho a la ciudad como una posibilidad social de lucha y teoría anticapitalista, que haga del territorio urbano un escenario de construcción de alternativas de apropiación y participación política y espacial, en camino a una sociedad que supere el capitalismo. En tercer lugar, se aborda el enfoque de la geografía posmoderna de Edward Soja, para quien el derecho a la ciudad no se restringe a la lucha anticapitalista, sino que articula formas de resistencia étnica, de género y cultural, como expresión de la 
Universidad Pedagógica Nacional

Facultad de Humanidades

diversidad de experiencias urbanas. En cuarto lugar, se establece la manera en que Ana Fani Alessandri Carlos asume el derecho a la ciudad, como forma de crítica tanto a la espacialización del capitalismo financiero, como a la apropiación de este concepto por parte del Estado en Brasil. Finalmente se proponen las conclusiones de esta reflexión y se señalan las posibilidades que para la investigación social de la ciudad abre el debate teórico y político sobre el derecho a la ciudad. Como se evidencia en este ensayo, el derecho a la ciudad continúa constituyendo un horizonte de análisis teórico y de acción política que permite asumir la ciudad como una posibilidad de creación colectiva para la realización de una vida común, no sin conflictos, pero cuyos habitantes puedan interpelar las lógicas espaciales del capitalismo.

\section{El derecho a la ciudad: el enfoque fundante de Henri Lefebvre}

Henri Lefebvre (1901-1991) construyó su hipótesis de trabajo sobre el derecho a la ciudad como la posibilidad y la capacidad de los habitantes urbanos y principalmente de la clase obrera, de crear y producir la ciudad. Su producción teórica sobre lo urbano se dio en un contexto intelectual, marcado por los agudos antagonismos sociales de Francia en la década de 1960 y las rupturas epistemológicas en las ciencias sociales del momento. Precisamente en 1967, Henri Lefebvre escribió un ensayo titulado El derecho a la ciudad, en el que con un énfasis filosófico y sociológico, planteó que el urbanismo moderno implementado por el Estado y el capital era una estrategia que, mediante la producción y racionalización del espacio, mercantilizaba la vida urbana. El urbanismo moderno, según Lefebvre, había generado una mayor segregación espacial, el predominio del valor de cambio del espacio ahora mercantilizado, y la imposibilidad de que los trabajadores pudieran participar en las decisiones sobre la ciudad, confinados en una vida urbana enajenada por el consumo, la fragmentación de la cotidianidad y la exclusión espacial. Por ende, Lefebvre enunció el derecho a la ciudad como el retorno de la clase obrera a la ciudad en calidad de productora del espacio y usufructuaria de su valor de uso. La experiencia urbana de la clase obrera y su cotidianidad no enajenada serían la fuente de las nuevas utopías urbanas. Esta estrategia de la revolución urbana socialista planteaba que la lucha obrera debía estar acompañada de iniciativas de investigación urbana (con iniciativas como las que planteaba el mismo Lefebvre) y acción política que posibilitarían a la clase obrera apropiarse de la ciudad, y así habilitarse para incidir en las decisiones sobre la ciudad (Lefebvre, 1972).

Cuando Lefebvre escribió sobre el derecho a la ciudad, las ciudades europeas pasaban por un periodo de reconstrucción urbana y económica, al que se denominó "Los Treinta Gloriosos" (19451973). La reconstrucción de posguerra, financiada por el Plan Marshall, implicó crecimiento económico y la expansión urbana para Francia y sus ciudades devastadas. El Estado francés implementó las propuestas urbanistas de Le Corbusier, urbanista francés para quien la ciudad debería ser reconstruida desde un orden espacial geométrico y racionalista, capaz de regular el orden social urbano. A partir de estos supuestos el Gobierno diseñó un gigantesco plan de viviendas en la periferia urbana, que si bien resolvió el problema de habitación para cerca de tres millones de familias obreras y de clase media, generó segregación espacial y precarización de la calidad de vida urbana (Fernández, 2013). Los gobiernos de "Los Treinta Gloriosos" patrocinaron la creación de centros de estudios urbanos financiados por el Ministére de l'équipement que contribuyeron a la institucionalización de la sociología urbana en Francia. En 1954, por ejemplo, se fundó el Centro de Sociología Urbana (Csu) dirigido por Paul-Henry Chombart de Lauew. En 1958 Alain Touraine fundó el Laboratorio de Sociología Industrial, actualmente Centro de Estudios de los Movimientos Sociales de la Escuela Práctica de Altos Estudios. Cuatro años después, en 1962, Henri Lefebvre fundó el Instituto de Sociología Urbana de la Universidad de Nanterre, que dirigió hasta 1975, y en 1967 François Fourquet, Félix Guattari y Anne Querrien fundaron el Centro de Estudios, Investigaciones y Formación 
Institucionales. A pesar de haber sido patrocinados por el Gobierno, la característica de estos centros fue la crítica marxista o antiautoritaria de las políticas urbanas (Busquet, 2014).

En ese contexto Lefebvre inició una crítica a la sociología y al urbanismo basado en los principios formulados por los Congresos Internacionales de Arquitectura Moderna (CIAM). Según él, al plantear la organización de la ciudad en funciones sociales compartimentadas (habitar, trabajar, consumir, educarse y distraerse), los CiAm habían contribuido de manera definitiva a la fragmentación de la vida en común, dejando al capitalismo y al Estado al mando de las decisiones sobre la vida urbana (Lefebvre, 1960). Para Lefebvre el urbanismo funcional lecorbusiano era tanto una ideología de clase como una estrategia burguesa de organización espacial. Al convertir la ciudad en un agregado de funciones separadas, el urbanismo moderno impedía una mirada de la ciudad como totalidad, lo cual dificultaba el proyecto de realización de la vida urbana como construcción colectiva (1978). Además, el urbanismo moderno impulsaba un proceso mundial de "urbanización completa" de la sociedad que ponía fin a la concepción de ciudad como construcción social disputada política y culturalmente por diferentes clases sociales y la fijaba como espacio libre para la producción capitalista (1978).

En el estudio de lo urbano, Lefebvre apeló a los textos de Engels sobre la clase obrera en la ciudad y a los Manuscritos económico-filosóficos de Marx y Engels, así como a los capítulos inéditos de El capital dados a conocer a mediados de la década de 1970 (Lefebvre, 1974). También fue importante su relación con el movimiento situacionista y su teoría de la alienación de las relaciones sociales en el capitalismo ${ }^{5}$. La influencia del situacionismo se dio después de

5 El situacionismo fue un movimiento artístico de vanguardia constituido en la década de 1950, el cual proponía una estética y una teoría crítica de la sociedad y la cultura contemporáneas. Su proyecto consistió en fusionar el arte y la vida, poniendo énfasis en los aspectos subjetivos de la lucha política y "politizando" la vida cotidiana y los malestares existenciales generados por la alienación capitalista. Entre sus representantes estuvieron el artista Asger Jorn (1914-1973), Cornelius Castoriadis (1922-1997) y Guy Debord (1931-1994), este último su principal representante, cuyo libro emblemático es La sociedad del espectáculo (1967). que Lefebvre fuera expulsado, en 1958, del Partido Comunista francés por sus críticas al marxismo soviético, al que consideraba dogmático y reduccionista en el análisis de la sociedad (De Souza, 1998). Entonces, se radicó en Estrasburgo como profesor. En esta ciudad, cuna del situacionismo, tuvo como estudiante a Guy Debord (1931-1994), líder de este movimiento. Con este intelectual compartió discusiones sobre la enajenación de la vida cotidiana por la modernidad capitalista y sobre la manera en que ésta atomiza a las personas y las convierte en consumidores aislados sin comunicación entre sí. Ante esta separación, la sociedad se tornaba en un espectáculo que enajenaba a los ciudadanos mediante el consumo masivo y dificultaba su acción anticapitalista (Debord, 1995). También, y con el propósito de hacer de la ciudad una obra, una creación, Lefebvre tomó de los situacionistas el planteamiento de los "experimentos urbanos". Basados en la deriva, estos "experimentos" eran propuestas de exploración urbana que invitaban a andar libremente en la ciudad, y que en sí mismos contradecían la planificación racional y prefiguraban la posibilidad de la nueva utopía urbana (Barnard, 2011). No obstante estos encuentros y relaciones, en 1965 el movimiento situacionista expulsó a Lefebvre tras una intrincada relación política y personal, mediada por el radicalismo situacionista y su tendencia a expulsar continuamente a quienes consideraba vacilantes. Andi Merrifield (2006), su biógrafo, reconstruyó el episodio que tuvo como punto de partida la acusación acerca del plagio que Debord hizo del texto que escribió Lefebvre sobre la Comuna de París en 1962, y cómo desde ese momento hasta 1965 se produjo el distanciamiento definitivo.

A partir de estos referentes teóricos y políticos Lefebvre sistematizó un conjunto de postulados de análisis urbano, para estudiar los cambios de las ciudades europeas de posguerra, que sería difundido en 1967 cuando publicó El derecho a la ciudad. Lefebvre explicó en este libro que la industrialización generalizada de la sociedad le había quitado su carácter de obra construida socialmente. La industrialización había masificado la producción de mercancías y llevado al predominio del valor de cambio sobre el valor de uso, haciendo 
Universidad Pedagógica Nacional

Facultad de Humanidades

de la ciudad una mercancía. Mientras en la ciudad medieval y mercantil el valor de uso orientaba parte del gasto urbano de los comerciantes - que hacían de la riqueza un medio para reafirmar sus privilegios con monumentos y festividades (consumo improductivo) - , en la ciudad resultante del proceso de industrialización y acumulación de capital, la burguesía industrial y financiera abandonó el consumo improductivo privilegiando el consumo productivo, y la inversión inmobiliaria generadora de ganancia (Lefebvre, 1975). Lefebvre denominó la sociedad urbana e industrial como sociedad de consumo, "sociedad burocrática de consumo dirigido", que hizo de la clase obrera una productora y a la vez consumidora de mercancías y de espacio mercantilizado. Por ejemplo, el acceso de los obreros a la propiedad sobre la vivienda resolvía el problema del habitar, pero tendía a centrar sus preocupaciones políticas en los derechos de propiedad, alejándolos de la acción política anticapitalista.

El habitar, entonces, fue subsumido por el hábitat. Antes de la urbanización generalizada, habitar era una actividad social que confería a los ciudadanos identidad urbana y por ende los habilitaba para la participación política. Con el proceso de urbanización, se redujo a ocupar una vivienda, esto es, se convirtió en una función separada de la actividad política. Las políticas de hábitat urbano se hicieron cada vez más una suma de imposiciones y controles de planificación, zonificación, usos del suelo, impuestas desde arriba y que obstaculizaban la participación ciudadana en las decisiones sobre los cambios urbanos (Lefebvre, 1975). Por consiguiente el derecho a la ciudad sería entonces la restitución de la visión de la totalidad y la lucha contra la enajenación de la vida cotidiana. Tal y como lo planteó Lefebvre:

El derecho a la ciudad no puede concebirse como un simple derecho de visita o retorno hacia las ciudades tradicionales. Solo puede formularse como derecho a la vida urbana, transformada, renovada. [...] ello supone una teoría integral de la ciudad y la sociedad urbana que utilice los recursos de la ciencia y del arte. Únicamente la clase obrera puede convertirse en agente, vehículo o apoyo social de esta realización. Aquí, como hace todavía un siglo, la clase obrera con su mera existencia niega y discute la estrategia de clase dirigente en su contra. (1975, p. 139)

Esta visión de totalidad permitía una participación informada a los trabajadores y a los ciudadanos para ejercer el derecho a la ciudad y consiguientemente la producción del espacio. Si bien Lefebvre reconoció que el capitalismo instrumentaliza el espacio para planificarlo y favorecer su reproducción, también consideró que es en el espacio donde surgen las posibilidades de transformación. Ante las isotopías, esto es, la tendencia a la uniformización y en consecuencia el control capitalista del espacio (a través, entre otros, de conjuntos habitacionales o centros comerciales), aparecen las heterotopías, esto es, las maneras diferentes de ocupar el espacio en resistencia al capital, y así mismo las utopías urbanas, los lugares de transformación radical urbana (Lefebvre, 1972).

Sin embargo, su insistencia en que el sujeto principal del derecho a la ciudad era la clase obrera, tuvo que ser modificada luego del reflujo revolucionario tras Mayo del 68 (Lefebvre, 1975b). El afianzamiento de la hegemonía burguesa lo llevó a considerar que había que reconocer la activa presencia de otros sujetos sociales no proletarios, como actores de la lucha por el derecho a la ciudad. Como escribió en 1974:

Hoy en día ya no bastan esas definiciones limitadas de la revolución. Una transformación de la sociedad supone la posesión y la gestión colectivas del espacio mediante una intervención constante de los "interesados", con sus múltiples, diversos y contradictorios intereses. (Lefebvre, 1974, p. 450)

Este espectro más amplio de actores urbanos se hacía necesario para este autor, por cuanto, todavía en la década de 1980, en los análisis urbanos críticos estaban presentes enfoques reduccionistas: la simplificación o el desconocimiento de los problemas de la ciudad por parte de varios marxistas y la sobrevaloración urbana del posmodernismo que reducían el análisis a los problemas de las clases medias, la cultura y las tecnologías. Para Lefebvre, el espacio 
atravesaba toda la sociedad, todas las clases, la base económica y la superestructura (1983).

Dos años antes de su muerte en 1991, escribió un último artículo en el que planteó la amenaza planetaria de la mundialización urbana neoliberal. Lefebvre (1989) vio en la globalización económica, financiera y tecnológica un incremento de la desigualdad y de la alienación. La urbanización planetaria y la aún mayor mercantilización de la ciudad, a juicio suyo, reclamaban el ajuste de su propia teoría de la transformación revolucionaria del capitalismo, tal y como había sido formulada a finales de la década de 1960 (Lefebvre, 1989). Sin embargo, serían otros autores los que años después propondrían nuevos redireccionamientos a las tesis esbozadas por Lefebvre.

\section{David Harvey: el derecho a la ciudad y la superación del capitalismo}

A partir de lo planteado por Lefebvre, David Harvey (1935) considera que el derecho a la ciudad expresado por los movimientos anticapitalistas urbanos es la posibilidad de transformar y recuperar la ciudad como bien común. No obstante, a diferencia de Lefebvre, postula la reivindicación de las "prácticas ciudadanas insurgentes" y no la lucha obrera, como el vehículo que puede materializar las utopías que intentan hacer del territorio un escenario de construcción de alternativas espaciales, que restrinjan los efectos urbanos de la apropiación capitalista del espacio ${ }^{6}$. Además, Harvey supone que en el proceso de construcción de una sociedad no capitalista, el derecho a la ciudad es solo un momento de una estrategia mayor de construcción de una sociedad no capitalista, por ende no es un punto de llegada, sino como él mismo afirma, una "estación de paso". No por esto es un asunto menor, es la tarea política urbana para el actual momento de lucha anticapita-

6 Harvey toma el concepto de "ciudadanía insurgente" de James Holston, para quien estas expresiones ciudadanas surgidas en las periferias urbanas populares, partiendo de los marcos legales vigentes, "empoderan, parodian, descarrilan o subvierten las agendas estatales", amplían las nociones de ciudadanía y abren el horizonte político hacia formas propias y autónomas de construcción política (Holston, 2008, pp. 3-35). lista. Para reconocer la manera en que Harvey asume el derecho a la ciudad es necesario contemplar dos componentes de su modelo explicativo, a saber, la producción social del espacio y de la ciudad, por parte del capital, y las posibilidades políticas y sociales de ejercer el derecho a la ciudad, un derecho cada vez más negado para amplios sectores de la población (Harvey, 2013).

Harvey plantea la "producción social del espacio" como una de las condiciones de la historia del capitalismo, noción a partir de la cual ha ido construyendo desde los años setenta su "teoría de la geografía histórica del capitalismo", esto es, de un materialismo histórico geográfico. Retomando a Lefebvre, Harvey (2004) sostiene que el capitalismo se reproduce produciendo, consumiendo y apropiando privadamente espacio, tiempo y trabajo. Sin embargo, aunque considera que Lefebvre propuso acertadamente que la producción y reproducción del capital solamente ocurren en el espacio, no atinó a precisar el mecanismo que hace esto posible. Según Harvey, la producción y reproducción capitalista genera sobreacumulación de excedentes (capital y trabajo), lo que ocasiona crisis económicas. Para sortear estas dificultades, el capitalismo realiza una serie de adecuaciones que Harvey denomina "ajustes espacio-temporales", los cuales se dan mediante la expansión geográfica y la reorganización espacial, esto es, a través de los llamados circuitos secundarios de capital. La expansión geográfica del capital crea nuevos paisajes marcados por la instalación de capital fijo (puertos, aeropuertos, carreteras, hidroeléctricas) en regiones importantes para la acumulación de capital. A medida que se expande geográficamente, el capital incrementa la competencia internacional por territorios, mercados y trabajo, lo que genera múltiples centros dinámicos de acumulación, sometidos a drásticas dinámicas de construcción y destrucción espacial, lo que explica las guerras, la violencia y el despojo de gentes y territorios en las últimas décadas (Harvey, 2004).

La expansión de las relaciones capitalistas a la vez produce disputas sociales y políticas entre los sectores y clases sociales que pueden resultar beneficiados o afectados por tales “ajustes 
Universidad Pedagógica Nacional

Facultad de Humanidades

espacio-temporales". Precisamente amplios sectores sociales son afectados por la producción capitalista del espacio, que, según Harvey, se presenta también como "destrucción creadora", o "acumulación por desposesión" (Harvey, 1990). En este sentido Harvey (2004) considera que el concepto de acumulación originaria o primitiva, propuesto por Marx, queda fijado en un momento histórico particular en el que el capitalismo no estaba completamente estructurado. No obstante, lo que encontró en sus análisis es que los rasgos descritos por Marx se intensifican en la actualidad a través de las dinámicas que impone el capital financiero que destruye capitales pequeños, ecosistemas y fuerzas sociales a través "de prácticas canibalísticas, depredadoras y fraudulentas".

Para Harvey (2007), es en la década de 1970 que se produce un cambio drástico en la acumulación del capital, y con ella la aparición de nuevas formas de "acumulación por desposesión", que afectan de manera particular el espacio urbano. Al pasar del régimen de acumulación fordista keynesiano al "régimen de acumulación flexible", comandado por los grandes capitales privados, que subordinan a los estados, se presentan situaciones como el incremento de la subordinación de países ante las imposiciones de la deuda externa, la mayor depredación de la naturaleza sometida a formas intensivas de explotación y la privatización a gran escala de los servicios sociales urbanos (Harvey, 2007).

La reducción de la capacidad del Estado-nación para controlar los flujos multinacionales de dinero ha llevado a que el capital financiero internacional busque negociar con los poderes locales. Para atraer la inversión, estos poderes locales diseñan diversas estrategias urbanísticas como la ampliación de infraestructura y equipamiento urbano, en lugares específicos de la ciudad. De acuerdo con Harvey, la inversión y el diseño para fragmentos urbanos ha impedido "diseñar un planeamiento urbano integral" (2007, p. 386). Además, esta competencia por dotar a las ciudades de elementos distintivos (ventajas competitivas) atractivos para la inversión de capital garantiza a los capitales una renta de monopolio, pues logran extraer ganancia al contro- lar ese elemento distintivo, específico. Para Harvey en este momento de acumulación flexible, "la urbanización capitalista tiende a destruir la ciudad como bien común social, político y vital” (2013, p. 125).

Es entonces a partir de una teoría sobre la producción social del espacio y los cambios vividos por las ciudades como consecuencia de las nuevas dinámicas del capital que Harvey propone su proyecto político de derecho a la ciudad, como parte de una estrategia de lucha anticapitalista. Al igual que Lefebvre, Harvey asume que es en el espacio construido donde pueden surgir las alternativas anticapitalistas, pero señala lo que considera insuficiencias de la propuesta de utopía espacial de Lefebvre, quien no se atrevió a proponer alternativas espaciales concretas por temor a que fueran cooptadas. "Para él — sostiene Harvey- la producción del espacio debe mantenerse siempre como una posibilidad infinitamente abierta" (2003, pp. 210-211), por lo que resulta difícilmente materializable. Harvey es enfático:

[...] el derecho a la ciudad tiene que plantearse, no como un derecho a lo que ya existe, sino como un derecho a reconstruir y recrear la ciudad como un cuerpo político socialista con una imagen totalmente diferente, que erradique la pobreza y la desigualdad social y que cure las heridas de la desastrosa degradación medioambiental. (2013, p. 202)

La posibilidad de que el derecho a la ciudad sea viable recae, para Harvey, en el desarrollo y la articulación de un conjunto de "prácticas políticas insurgentes" en diversas escalas espacio-temporales o "teatros de actividad insurgente" teórica y práctica. Estas prácticas incluyen diferentes escalas, que van desde el espacio personal y comunitario hasta la participación en las instituciones del Estado. Harvey aspira a que la práctica política insurgente convierta a los sujetos sociales urbanos en "arquitectos insurgentes", diseñadores de utopías espaciales no capitalistas, en las que la articulación y diferenciación del espacio personal y del colectivo, así como las relaciones sociales entre personas y con las instituciones mediadoras de regulación social y los entornos ambientales no sean mediadas por el capital, sino por el bien común. El autor reivindica 
la autonomía de la acción política en el espacio, así como la posibilidad de incidir en la gestión urbana (Harvey, 2003).

Las prácticas políticas insurgentes propuestas por Harvey producen una ciudadanía insurgente que está incidiendo en la gestión política urbana, por ejemplo los logros en torno a la definición colectiva de presupuestos participativos urbanos en ciudades de Brasil, que evidencian expresiones prácticas del ejercicio del derecho a la ciudad. Pero el derecho a la ciudad no puede asumirse, según Harvey, como un "fin en sí mismo", que puede existir de forma paralela a la lógica del capital. Su apuesta es de largo aliento:

Hay que derrocar y remplazar la totalidad del sistema capitalista de acumulación perpetua, junto con sus estructuras asociadas de clase explotadora y poder estatal. La reivindicación del derecho a la ciudad es una estación intermedia en la ruta hacia ese objetivo. (2013, p. 16)

En este orden de ideas, el derecho a la ciudad vendría a ser una condición que permite a los seres humanos reconstruirse al replantear las dinámicas a través de las cuales el capital domina espacialmente la ciudad. Por tanto, ante la hegemonía del capital, corresponde la exigencia de "mayor control democrático sobre la aplicación a la urbanización de los excedentes" (Harvey, 2013, p. 46). Es por esto que Harvey plantea el derecho a la ciudad como una estación de paso, que no se queda en el llamado a mejorar el capitalismo, sino que se contempla en perspectiva de un orden socio-espacial no capitalista. En ese mismo sentido el derecho a la ciudad no puede limitarse a reclamar justicia social y redistributiva, ya que el capitalismo se adapta a diferentes distribuciones de renta y riqueza (2014).

Para Harvey, no cabe hoy una actitud política de conciliación liberal, pues la dinámica del capital no busca conciliación de clase. Harvey sentencia que solo un proyecto de humanismo revolucionario, que movilice a la sociedad contra los efectos del capital sirve para actuar en estos tiempos. Como parte de esta postura teórica y política, y en una alianza con el gobierno de Rafael Correa, Harvey creó en Ecuador el Centro Nacional de Estrategia para el Derecho al Territorio-Cenedet, como un centro de investigación crítica transdisciplinaria y de docencia, cuyo propósito es fortalecer los proyectos políticos y sociales en una perspectiva de sociedad posneoliberal. Esta iniciativa deberá tenerse en cuenta para analizar las posibilidades y los desarrollos de su proyecto político.

\section{Edward Soja: la justicia espacial en la posmetrópolis y los límites revolucionarios del derecho a la ciudad}

Teniendo en cuenta la teoría de Lefebvre sobre la "producción social del espacio", el geógrafo estadounidense Edward Soja (1940) plantea que el derecho a la ciudad no puede restringirse a la lucha contra los efectos del capitalismo en el espacio urbano. A diferencia de Harvey, para Soja la lucha anticapitalista no agota las posibilidades de reivindicación de la justicia espacial y del derecho a la ciudad. Por el contrario, nuevas dimensiones espaciales que escapan al análisis de clase, como el género, la etnicidad, o la cultura, evidencian la diversidad de formas de experimentar la ciudad y de buscar justicia espacial. Soja reivindica en su investigación sobre la ciudad y el derecho a la ciudad una mirada "ecléctica", que busca incluir los aportes a la teoría espacial de la ciudad de Henri Lefebvre y los análisis sobre espacios e intersticios múltiples propuestos por Michel Foucault, el feminismo posmoderno y los estudios culturales. A partir de estos referentes se diferenció de David Harvey, para quien el derecho a la ciudad es la estación intermedia de un proyecto político mayor de lucha anticapitalista. Por el contrario, Soja reivindicó la lucha por la justicia espacial, que trasciende el contenido de clase del marxismo y se afirma en las posibilidades culturales, simbólicas y sociales que surgen en los intersticios de la posmetrópolis (Soja, 2013). Su planteamiento sobre el derecho a la ciudad se sostiene en tres elementos centrales: la construcción social del espacio, la ciudad entendida como posmetrópolis y las luchas por la justicia espacial y la democracia regional.

Para Soja la construcción social del espacio en el capitalismo es un proceso en el que intervienen 
Universidad Pedagógica Nacional

Facultad de Humanidades

multitud de fuerzas, no solamente económicas y de clase, sino también culturales y políticas. Para captar esa diversidad de fuerzas utiliza estrategias metodológicas provenientes de distintas corrientes teóricas. Su punto de partida fue Henri Lefebvre, a quien reivindicó como pionero del análisis posmoderno y de quien tomó las categorías de análisis del espacio: espacio percibido, espacio concebido y espacio vivido. Soja propuso metodológicamente como primer espacio aquel que engloba el mundo material y real; como espacio concebido, aquel que incluye las representaciones mentales e imaginarias $\mathrm{y}$, como tercer espacio, aquel generado a partir de los anteriores y que rompe el dualismo entre lo concebido y lo percibido, y que permite así aproximarse a la complejidad de la experiencia vivida. Es este espacio, marcado por lo opuesto y lo contradictorio, el que posibilita la creación de alternativas al capitalismo y el derecho a la ciudad (Soja, 1996). Además de la trilogía espacial de Lefebvre, Soja incluyó el concepto de Heterotopía (yuxtaposición de lugares en un mismo espacio) de Foucault y la deconstrucción del teórico poscolonial Homi Bhabha, que igualmente cuestiona la estructura binaria de la modernidad (Soja, 1996). A partir de estas herramientas, Soja describe el espacio como escenario de control y normalización y a la vez de subversión y posibilidad en la construcción de alternativas y relaciones espaciales que escapan a la hegemonía de las fuerzas hegemónicas de la posmetrópolis.

Reconocer las alternativas espaciales, y en consecuencia las posibilidades de reclamo de la justicia espacial y el derecho a la ciudad, implica, según Soja, tomar distancia de las diadas binarias como exterior-interior, público-privado, masculinofemenino, y encontrar en los espacios híbridos o zonas fronterizas la potencia para la construcción de alternativas (1996). Por consiguiente, su objeto de estudio es la ruptura y la hibridación especial con que las alternativas espaciales logran impugnar la jerarquización socio-espacial promovida por el capitalismo en las posmetrópolis. El modelo de referencia empírica es para Soja la ciudad norteame- ricana de Los Ángeles ${ }^{7}$. Una de las expresiones de la hibridación espacial es la descripción de "paradojas socio-espaciales", con las que Soja explica procesos urbanos de las posmetrópolis. Un primer juego de paradojas socio-espaciales es la dinámica simultánea de desindustrialización y reindustrialización, que permite explicar cómo a pesar de que en la década de 1980, en ciudades como Los Ángeles, se puso fin a las grandes cadenas de montaje automotriz pero se dio el surgimiento de pequeñas industrias textiles y el auge de las industrias militar y cinematográfica; estas últimas incorporaron trabajadores altamente cualificados, lo que a su vez ha generado segregación sociolaboral (Soja, 2013). Otra de las paradojas es la simultaneidad de descentralización y recentralización. Históricamente, el crecimiento urbano de Los Ángeles fue descentralizado industrial y residencialmente gracias a la red de infraestructura que fue diseñada en función de la localización periférica de la industria automovilística; no obstante, el centro de la ciudad continuó siendo un importante pivote del Gobierno, las finanzas y el comercio. Las paradojas espaciales conducen a comprender el espacio como multidimensional, cambiante y contingente, y por ende a las posmetrópolis, según Soja, como producto de múltiples fuerzas que transforman la vida urbana, en las que se controvierten diferentes posibilidades, entre ellas las alternativas espaciales, que a pesar de estar inmersas en las dinámicas del control del capital, no pueden ser reducidas por este (2008).

En este sentido, analizar la posmetrópolis, su diversidad y las oportunidades para la justicia espacial, solo es posible para Soja desde una metodología ecléctica que incorpore distintos "discursos" que expliquen la diversidad encontrada en la posmetrópolis. La posmetrópolis es simultáneamente metrópolis industrial posfordista flexiblemente especializada; ciudad, región urbana globalizada o cosmópolis; megaciudad con gigantescas zonas suburbanas, o exópolis; ciudad fractal de intensificadas desigualdades y polarización social; ciudad

7 Gran parte de sus análisis han sido realizados a partir del estudio de la ciudad de Los Ángeles, que Soja considera el caso paradigmático de la reestructuración espacial capitalista de finales del siglo xx y de las nuevas formas de ejercicio del derecho a la ciudad. 
archipiélago carcelario de ciudades fortificadas; y "simcity hiperreal", donde la vida diaria de sus habitantes transita "como si fuera un juego de ordenador" (Soja, 2008, p. 22). Estas descripciones de la posmetrópolis son realizadas por diferentes teorías urbanas o "discursos", los cuales, según Soja, permiten también evidenciar cómo se incrementan de manera simultánea las desigualdades económicas y extra-económicas (raciales, de género, étnicas), con "consecuencias destructivas tanto en los entornos urbanos como en los naturales" (2008, p. 564). Las formas de contrarrestar estas injusticias y desigualdades se encuentran en las luchas por justicia espacial y por democracia territorial, que buscan redireccionar los nuevos procesos de urbanización capitalista.

Es desde el análisis espacial y la diversidad encontrada en la posmetrópolis que Soja considera posible la búsqueda de justicia espacial y democracia territorial, las formas de dar concreción al derecho a la ciudad. El levantamiento urbano que sacudió la ciudad de Los Ángeles luego del asesinato del afroamericano Rodney King, apaleado por agentes de LAPD en 1992, fue para Soja la expresión de demandas de justicia espacial, ante la crisis de la posmetrópolis. El autor recurre a la diversidad urbana, descrita en los discursos planteados, para explicar estas luchas urbanas. La anunciada prosperidad de la economía posfordista había sucumbido ante las elevadas tasas de desempleo en todos los sectores económicos, y la cosmópolis como ciudad de migraciones multiculturales era sacudida por el incremento de hambrunas y familias sin techo. La rebelión de los afroamericanos no se concentró en los viejos centros de la ciudad, sino que alcanzó las ciudades frontera y las áreas suburbanas, la exópolis, habitadas por clases medias y altas que vivieron la rebelión como un "ataque de locura generalizado" que llegó hasta sus territorios pensados como seguros e inalcanzables por los pobres. No había "ningún lugar para ocultarse”, afirmó Soja (2008, pp. 545-558). Ante los levantamientos, la población blanca asumió posturas de derecha, con el fin de presionar para que se pusiera fin a la educación multicultural y a los derechos civiles; una suerte de nativismo blanco de derechas, o como definió Soja, una “insurgencia de los hombres blancos heterosexuales reaccionarios" (2008, p. 561). Sin embargo, al mismo tiempo emergieron discursos críticos sobre las ciudades, sustentados en el feminismo posmoderno, la teoría queer, el posmarxismo y el poscolonialismo, que alimentaron demandas urbanas por el logro de una democracia regional, que incluyera el mejoramiento de la inversión en capital social o la justicia distributiva de la renta urbana. A partir de estas demandas, Soja consideró que era posible ver cómo

[...] cobra nueva vida un antiguo concepto de derechos y responsabilidades de los ciudadanos, el re-empoderamiento de la sociedad civil y la demanda de los años sesenta para obtener un mayor derecho a la ciudad o le droit à la ville, la mordaz frase de Henri Lefebvre que jugó un papel clave en la movilización de Mayo de 1968 para el levantamiento en París. (2008, p. 562)

La difusión de una mayor sensibilidad hacia las cuestiones interculturales, transnacionales y de género, abrieron la puerta a luces esperanzadoras para el futuro de la democracia en la ciudad. Además, para Soja la lucha por la justicia espacial es un problema eminentemente urbano, pues es allí, en los intersticios del espacio regulado, donde brotan nuevas expresiones de justicia espacial. En su libro En busca de justicia espacial, analiza precisamente varios casos que demuestran cómo la sociedad puede lograr la justicia espacial luchando desde tales intersticios. Uno de ellos es la lucha por el derecho al transporte público masivo en Los Ángeles. En octubre de 1996, después de jornadas de movilización que concluyeron en un referendo ciudadano, la Autoridad de Transporte Metropolitano debió acatar un fallo judicial para reparar la discriminación en contra de la gente pobre de la ciudad, que no disponía de vehículo particular y que tampoco contaba con un buen sistema de transporte público. Esta demanda obligó a la ciudad a invertir en la mejora significativa del mismo (Soja, 2014). Otro ejemplo analizado por Soja es el de la resistencia urbana ante las transformaciones socio-espaciales ocurridas luego del atentado a las Torres Gemelas 
Universidad Pedagógica Nacional

Facultad de Humanidades

en 2001. Tales transformaciones incluían medidas regresivas en materia de derechos civiles y medidas antiinmigración, entre las cuales se destacan el reemplazo de empleados de seguridad en los aeropuertos por agentes del servicio civil federal $y$ el incremento de la seguridad en ciudades y fronteras (Soja, 2014). Como respuesta, multitudinarias manifestaciones (como el "Great American Boycott" del 1. ${ }^{\circ}$ de mayo de 2006) convocaron la solidaridad con los migrantes y rechazaron las políticas discriminatorias, lo que a la larga llevó a fortalecer las luchas por la justicia espacial y el derecho a la ciudad (Soja, 2014). Como parte de esta ola de inconformismo espacial, Soja ubica la lucha librada en 2004 por los habitantes del suburbio de Inglewood, en las afueras de Los Ángeles, contra el monopolio Wal-Mart. Esta empresa recibió una de sus mayores derrotas cuando la población ganó, con el $60 \%$ de los votos, una consulta popular que rechazaba la construcción de un gigantesco centro comercial. La población de Inglewood representada por sindicatos, líderes comunitarios y activistas sociales, afroamericanos e hispanos cuestionaba los bajos salarios y el peligro que este centro comercial implicaba para el pequeño comercio suburbano. En la campaña a su favor Wal-Mart invirtió un millón de dólares para convencer a la gente de los beneficios que traería su nuevo centro comercial, pero esto no fue suficiente (Soja, 2014). Además, la creación en 2007 de la Alianza por el Derecho a la Ciudad, con una fuerte base social en Los Ángeles, según Soja, ha expandido y establecido nexos con académicos y organizaciones civiles y comunitarias, y permitido la coordinación de experiencias de resistencia espacial en diversas ciudades de Estados Unidos.

Si bien la crisis de la posmetrópolis ha significado el surgimiento de movimientos y luchas por la justicia espacial, también ha posibilitado el surgimiento de coaliciones políticas locales y regionales que discuten temas como a quién debe beneficiar el incremento en la productividad y la competitividad económica regional. Estas coaliciones demandan una concertación con las instituciones locales, así como una mayor inversión de capital social, que mejore las condiciones laborales y salariales de la fuerza de trabajo. Aunque esa democracia regional puede tener expresiones conservadoras, Soja considera que:

Estos desarrollos están haciendo que se eleve la conciencia del grado en el que las estructuras administrativas de gobierno, largamente afianzadas en la fragmentada postmetrópolis, constriñen fuertemente las posibilidades de obtener una mayor justicia y democracia. Lo que está llevando a algunos a replantearse la dependencia exclusiva del gobierno local en ámbitos tales como el municipio y el condado, y a las nuevas visiones para un sistema de gobierno regional democrático más receptivo a las necesidades reestructuradas del espacio urbano postmetropolitano. (2008, pp. 559-571)

En síntesis, Soja plantea que el derecho a la ciudad no puede reducirse a las luchas contra el capitalismo, ya que existen muchas fuerzas que dan forma a las geografías injustas, como el racismo, el fundamentalismo religioso, la discriminación por razón de género, la injusticia ambiental. De ahí que más que una etapa intermedia, el derecho a la ciudad sea para Soja un horizonte de posibilidades inmediatas que están contribuyendo, desde pequeñas expresiones, a crear relaciones espaciales justas y democráticas.

\section{Ana Fani Alessandri Carlos: el derecho a la ciudad en la ciudad del capital financiero y en la ciudad de los gobiernos de izquierda}

Ante nuevos acercamientos al derecho a la ciudad, la geógrafa urbana brasilera Ana Fani Alessandri Carlos (1950) ha intentado recuperar el sentido marxista del mismo propuesto por Lefebvre. Según Carlos, el derecho a rehacer la ciudad y la vida urbana tiene hoy dos tareas fundamentales: recuperar el espacio público urbano apropiado por el capital financiero, y mantener la autonomía política y revolucionaria del derecho a la ciudad, ahora que en Brasil ha sido incorporado como discurso estatal. Su propuesta resulta muy interesante porque articula dos dinámicas que no están presentes en 
los otros autores: el dominio del capital financiero sobre la ciudad y, simultáneamente, las políticas urbanas de un gobierno de izquierda que plantea la planificación del espacio urbano desde el derecho a la ciudad. La incorporación del derecho a la ciudad en la planeación urbana se estableció en 2001 con la Ley de la Ciudad y se reafirmó luego, durante el primer gobierno de Lula da Silva, con la creación del Ministerio de la Ciudad (2003).

Los análisis propuestos por Carlos se entroncan en la geografía marxista brasileña, que desde la década de 1960 mantuvo apropiaciones críticas de las teorías de Lefebvre ${ }^{8}$. En sociología fueron Florestan Fernandes, José de Souza Martins y Fernando Enrique Cardozo quienes dialogaron con el marxismo y con Lefebvre, mientras en el campo de la geografía fue Milton Santos (1926-2001). Este último, quien tiene una gran influencia en el trabajo de Carlos, se vinculó a la Universidad de São Paulo, donde enseña Carlos, a mediados de la década de 1980, luego de un largo exilio que lo llevó a recorrer diversos países y a relacionarse en las décadas de 1960 y 1970 con geógrafos como los franceses Henri Lefebvre y Pierre Georges, y el estadounidense David Harvey (Martin, 2007).

Carlos se propuso llevar a cabo, desde el marxismo, una revalorización de los aportes que a través del espacio y de lo urbano había hecho Lefebvre a la teoría de la reproducción capitalista. Según Carlos, la contradicción fundamental del capitalismo, señalada por Marx, entre producción social y apropiación privada se materializa en el espacio urbano. Esta autora, siguiendo a Lefebvre, entiende la ciudad como una construcción colectiva y conflictiva en la que participan diversas clases sociales. Lo urbano como producto de aspiraciones y necesidades sociales diversas es escenario de confrontación entre las tendencias a la mercantilización y privatización del suelo urbano para favorecer la circulación de mercancías, materias primas y mano de obra, y la

8 En una tradición de pensamiento geográfico marxista se conformó en 2001 el Grupo de Estudios sobre São Paulo (GESP), orientado a la formación de geógrafos y a la investigación de las dinámicas espaciales urbanas de Brasil, coordinado actualmente por Ana Fani Alessandri Carlos. tendencia al ejercicio de la ciudadanía y al derecho a la ciudad. Este último, según la autora, estaría encarnado en los habitantes urbanos que se resisten a la eliminación de los espacios de encuentro, fiesta, creación y apropiación que son fundamentales para la vida urbana (1992). Para comprender esta afirmación, resulta útil la definición de ciudad aportada por Carlos:

A cidade, enquanto construção humana, é um produto histórico-social e nesta dimensão aparece como trabalho materializado, acumulado ao longo do processo histórico de uma série de gerações. Expressão e significação da vida humana, obra e produto, processo histórico cumulativo, a cidade contém e revela ações passadas, ao mesmo tempo em que o futuro, que se constrói nas tramas do presente -o que nos coloca diante da impossibilidade de pensar a cidade separada da sociedade e do momento histórico analisado. (Carlos, 2017, p. 11)

Sin embargo, apunta Carlos, el capitalismo tiende a que sectores poderosos se apropien de la ciudad, ya sea por la acumulación de tierras, los negocios inmobiliarios, el control del trabajo o el monopolio de las decisiones. En metrópolis como São Paulo, esta apropiación privada se da en cada momento del ciclo del capital: producción, distribución y consumo. Por ejemplo, el crecimiento del sector financiero impone normas de competitividad, desarrollo de nuevos servicios tecnológicos y cambio de los establecimientos industriales, que modifican las ciudades en la competencia que desarrollan entre sí por alcanzar el estatus de ciudades de talla mundial (Carlos, 2001).

Además, afirma Carlos, en el actual ciclo de reproducción del capital, la economía metropolitana que fue liderada, por la producción industrial, en el caso de São Paulo, ha dado paso al crecimiento del sector terciario moderno (servicios, comercio, finanzas) como condición para el desarrollo en una economía globalizada (2001). Aún más, las inversiones del capital financiero en el espacio urbano, a diferencia del capital industrial, no necesitan estar fijadas espacialmente. Con la construcción de edificios corporativos destinados a la economía 
Universidad Pedagógica Nacional

Facultad de Humanidades

de servicios, el capital invertido en construcciones no se inmoviliza, puesto que ya no compra sino que alquila oficinas, lo que garantiza la flexibilidad y permite que en momentos de crisis, el capital se desplace hacia sectores más rentables de la economía (Carlos, 2008).

Asimismo, Carlos busca comprender el impacto de este tipo de urbanismo en la vida y experiencia cotidiana de las personas. El capital financiero transforma la ciudad y a la vez altera la cotidianidad, mediante la modificación de la experiencia del tiempo y el espacio. El tiempo cotidiano, asociado en la ciudad a un espacio construido que confiere identidad social, es reemplazado por el tiempo efímero, es decir el tiempo del capital financiero caracterizado por cambios abruptos, inesperados, de la vida cotidiana, como la posibilidad de perder el empleo en cualquier momento de la vida, o someterse a jornadas laborales flexibles. Adicionalmente, agrega Carlos, el espacio, el lugar de construcción de vida en común es sometido a la dinámica del espacio amnésico, el espacio del capital financiero, sin marcas de memoria social a largo plazo (2014). Los lugares de la ciudad construidos como espacios de memoria y comunidad van siendo demolidos o reestructurados al ritmo de inversiones inmobiliarias. Afirma Carlos:

La ciudad vivida como fragmento reduce las posibilidades de entrelazamiento de las acciones capaces de permitir la renovación de los eventos cotidianos que marcan la vida, dándole sentido. Esta viene demostrando la degradación de las condiciones de trabajo, la deterioración de las condiciones de habitación en áreas delimitadas por barreras físicas, edificios cercados, condominios fortificados; el espacio puntuado de edificios majestuosos que llevan la marca de arquitectos famosos; centros comerciales; el encerramiento de barrios con garitas y calles bloqueadas al transporte, rediseño de las líneas de autobuses que impiden accesos. Con el desalojo de las calles de los barrios en el contexto de su explosión presenciamos la deterioración de las relaciones de vecindad, marcadas por la intolerancia y el prejuicio, de las fiestas que escasean o se espectacularizan imponiéndose como tradición del otro (caso del halloween en São Paulo) produciendo un nuevo cuadro de representación que orienta la vida, presa cada vez más en un espacio privado. (2014, p. 4)

No obstante, la autora considera que esta apropiación privada de la ciudad, a pesar de fragmentar y empobrecer la experiencia vital de los ciudadanos, no se impone de manera absoluta, sino que es modificada y resistida desde los "residuos irreductibles a la lógica capitalista”, que se expresan en prácticas y luchas por la reapropiación y recreación del espacio urbano, como una lucha de clases con dimensiones espaciales (2014). En estos residuos surgen modos de apropiación por el uso, ligados a lo cotidiano, en donde memoria y acción se articulan en la construcción de identidad. Para Carlos, las manifestaciones que en São Paulo reclamaban el derecho a un mejor sistema de transporte público se caracterizaron por la ocupación o el retorno al espacio público urbano, que es "antes de nada, el lugar de la reunión, del encuentro, de la proximidad entre miembros de una determinada sociedad" (2014, p. 14). Este tipo de acción política urbana abrió las condiciones para que el problema del derecho a la ciudad, como discurso que cuestionaba las implicaciones sociales del modelo urbanístico del gran capital, se convirtiera en un tema público desde mediados de la década de 1990 y llevara a Ignacio Lula da Silva a la presidencia del país en el año 2002. Efectivamente, el Estatuto de la Ciudad aprobado en 2001 logró el reconocimiento de los movimientos sociales como actores y productores de la ciudad 9 .

Sin embargo, contrario a lo esperado, Carlos sostiene que lo ocurrido desde entonces ha sido la reducción del derecho a la ciudad a una representación minimalista. Se ha logrado el acceso a servicios urbanos, pero a costa de ignorar un proceso histórico mayor: la dominación del capital financiero sobre la ciudad. Sostiene Carlos que [n] o limite último, podemos afirmar que o que aparece

9 Numerosos académicos cercanos a los gobiernos del Partido de los Trabajadores, PT, han señalado que este papel intervencionista del Estado en la ciudad significa un retroceso y una regulación del capital financiero, así como una mejora de las condiciones de vida y la participación política de los habitantes urbanos de Brasil (Santos y Rossbach, 2010). 
como "direito à cidade" está circunscrito ao que o Estado está disposto a ceder na gestão da cidade, sem todavia incomodar a realização do circuito do capital, ao contrário, criando plenas condições para sua realização. (2007, p. 109)

Adicionalmente esta versión minimalista del derecho a la ciudad, a juicio de Carlos, sirve para encubrir el nuevo papel del Estado como garante del proceso de acumulación capitalista bajo el discurso del "desarrollo sustentable". El mismo discurso que, en una supuesta regulación social, le asigna a la gran propiedad privada el carácter de "función social", escondiendo su carácter segregador e injusto.

Ante la tendencia a banalizar el derecho a la ciudad y a la cooptación de las luchas urbanas por el Estado regulador del gobierno de izquierda, Carlos retoma el llamado de Lefebvre a elaborar una crítica radical del Estado y el capital. Esto es, una crítica que apropiada por los movimientos sociales impugne las formas de planear la ciudad, supeditadas al ciclo de acumulación capitalista protegido por el Estado, y conduzca a la construcción social de una ruptura que proyecte la necesidad de apropiación humana del espacio y la vida urbana. Según Carlos:

É assim que o direito à cidade acentua a noção de projeto para a sociedade capaz de esclarecer o caminho em direção à realização da mudança total, questionando (como possível-impossível) o fim da propriedade privada, a destruição do Estado e da realização plena do cidadão em um outra cidade. (2007, pp. 118-119)

Carlos señala las limitaciones de enunciar el derecho a la ciudad, sin situarlo en un análisis más amplio de las dinámicas del capitalismo, su relación con el Estado y las posibilidades de los movimientos sociales.

\section{Conclusiones}

En este ensayo se abordó el derecho a la ciudad propuesto por Henri Lefebvre y tres reapropiaciones realizadas por autores que, compartiendo el análisis marxista o postmarxista, proponen diferentes análisis teóricos del concepto así como diversas implicaciones políticas del mismo. Henri Lefebvre construyó su hipótesis de trabajo sobre el derecho a la ciudad como la posibilidad y la capacidad de los habitantes urbanos, principalmente de la clase obrera, de crear y producir la ciudad. Con base en su planteamiento, David Harvey asume el derecho a la ciudad expresado por los movimientos anticapitalistas urbanos, como la posibilidad de transformar y recuperar la ciudad como bien común. Sin embargo, a diferencia de Lefebvre, postula que las "ciudadanías insurgentes" y no la lucha obrera son la forma y el vehículo que pueden materializar las utopías por hacer del territorio un escenario de construcción de alternativas espaciales en diversas escalas, que van de lo personal a lo regional, y que pueden contribuir a restringir los efectos urbanos de la apropiación capitalista del espacio.

A diferencia de lo propuesto por Harvey, Edward Soja plantea que el derecho a la ciudad no puede restringirse a la lucha contra el capitalismo. Para este autor la lucha anticapitalista no agota las posibilidades de reivindicación de la justicia espacial y del derecho a la ciudad. Por el contrario, nuevas dimensiones espaciales, que escapan al análisis de clase, como el género, lo étnico, lo cultural, evidencian la diversidad de formas de experimentar la ciudad y buscar justicia espacial. Por último, Ana Fani Alessandri Carlos, buscando recuperar el sentido marxista del enfoque del derecho a la ciudad propuesto por Lefebvre, considera que el derecho a rehacer la ciudad y la vida urbana, implica que los ciudadanos disputen tanto el espacio público urbano, que está al servicio del capital financiero, como el repertorio del derecho a la ciudad, cooptado por el Estado.

Estas variaciones en las formas de conceptualizar el derecho a la ciudad están asociadas a los cambios urbanos que han traído la globalización capitalista y neoliberal y se fundan tanto en los marcos conceptuales y metodológicos del marxismo, como en aproximaciones más contemporáneas, como los estudios culturales y la decolonialidad. El concepto de derecho a la ciudad, incluidas sus reapropiaciones, constituye un valioso repertorio para la investigación social de las transformaciones económicas, culturales, 
Universidad Pedagógica Nacional

Facultad de Humanidades

morfológicas, tecnológicas, y políticas urbanas, por cuanto permiten pensar la ciudad como un hecho histórico social total, o con perspectiva de totalidad, ya sea asumiendo diferentes escalas analíticas (lo personal, lo local, lo regional o lo global) o estableciendo múltiples conexiones con ayuda de una perspectiva de análisis interdisciplinario.

Adicionalmente, y en un sentido político, el derecho a la ciudad contribuye a desnaturalizar los hechos urbanos que la enajenación capitalista tiende a presentar como al margen de la experiencia social, mientras ocultan su relación con las dinámicas del capital. Al proponer múltiples miradas sobre la ciudad, los teóricos del derecho a la ciudad aportan una comprensión de la ciudad como espacio social vivo y cambiante, lo que alimenta las aspiraciones colectivas de mejoramiento de la calidad de vida a partir de la acción política, ya sea en diferentes escalas de participación o producción de ciudad. Finalmente el derecho a la ciudad tiende un puente valioso entre la producción de conocimiento social, y los conflictos y procesos urbanos, permitiendo que saber y realidad se modifiquen y complejicen de manera reflexiva. Esta fue precisamente una de las premisas a las que aspiró Lefebvre: una vida urbana en común informada a la vez por un saber riguroso y crítico sobre la ciudad.

\section{Referencias bibliográficas}

Barnard, A. (2011). The situationists and the right to the city. International RC21 Conference, Amsterdam. Recuperado el 10 de marzo de 2015 de http:// www.rc21.org/conferences/amsterdam2011/edocs/ Session\%2018/RT18-2-Barnard.pdf.

Busquet, G. (2014). La sociología urbana francesa y la evolución de las políticas urbanas de los años 1960 a los años 1980: ¿posibilidades, impermeabilidades o afinidades electivas? Empiria. Revista de Metodología de Ciencias Sociales, 27.

Carlos, A. F. A. (1992). La cidade. São Paulo: Contexto.

Carlos, A. F. A. (2001). São Paulo Hoje: As contradições no processo de reprodução do espaço. Scripta Nova Revista Electrónica de Geografía y Ciencias Sociales Universidad de Barcelona, 88. Recuperado el 10 de marzo de 2015 de http://www.ub.edu/geocrit/sn-88.htm.
Carlos, A.F.A. (2007). O espaço urbano. Novos escritos sobre a cidade, São Paulo: FFLCH.

Carlos A. F. A. (2008). De la 'geografía de la acumulación' a la 'geografía de la reproducción': un diálogo con Harvey. Geocrítica. X Coloquio Internacional de Geocrítica, Barcelona, 26-30 de mayo, Universidad de Barcelona. Recuperado el 10 de marzo de 2015 de http://www.ub.edu/geocrit/-xcol/126.htm.

Carlos A. F. A. (2014). La ciudad como privación y la reapropiación de lo urbano como ejercicio de la ciudadanía. Scripta Nova. Revista Electrónica de Geografía y Ciencias Sociales, 493. Recuperado el 10 de marzo de 2015 de http://www.ub.edu/geocrit/sn/ sn-493/493-08.pdf.

Castells, M. (1998). La cuestión urbana. México: Siglo XXI. [1972].

Costes, L. (2014). Neoliberalizatio and Evolution of the 'Right to the City'. Justice spatiale-spatiale justice. 6.

Dávalos, P. (2011). La democracia disciplinaria. El proyecto posneoliberal para América Latina. Quito: Cooperación para el Desarrollo de la Educación Universitaria (Codeu).

De Souza M., J. (1998). Florestan. Sociología e Consciencia Social no Brasil. São Paulo: Editora da Universidade de Sao Paulo.

Do Rio Caldeira, T. (2007). Ciudad de muros. Barcelona: Gedisa.

Goonewardena, K. (2001, sep-feb). Henri Lefebvre y la revolución de la vida cotidiana, la ciudad y el Estado.

Harvey, D. (1990). Los límites del capitalismo y la teoría marxista. México: Fondo de Cultura Económica. [1982].

Harvey, D. (2003). Espacios de esperanza. Madrid: Akal. [2000].

Harvey, D. (2004). El “nuevo" imperialismo: acumulación por desposesión. Socialist Register. 40. Recuperado el 10 de marzo de 2015 de http://biblioteca.clacso. edu.ar/gsdl/collect/clacso/index/assoc/D8555.dir/ harvey.pdf

Harvey, D. (2007). Espacios del capital. Hacia una geografía crítica. Madrid: Akal. [2001].

Harvey, D. (2008). París capital de la modernidad. Madrid: Akal. [2006].

Harvey, D. (2013). Ciudades rebeldes. Del derecho a la ciudad a la revolución urbana. Madrid: Akal. [2012].

Harvey, D. (2014). Diecisiete contradicciones y el fin del capitalismo. Quito: Editorial IAEN. 
Holston, J. (2008). Insurgent citizenship: Disjunctions of democracy and modernity in Brazil. Nueva Jersey: Princeton University Press.

Lefebvre, H. (1960). Les nouveaux ensembles urbains. Un cas concret: LacqMourenx et les problèmes urbains de la nouvelle classe ouvrière. Revue française de sociologie 1, 2.

Lefebvre, H. (1967). El marxismo sin mitos. Buenos Aires: A. Peña Lillo Editor.

Lefebvre, H. (1972). La revolución urbana. Madrid: Alianza.

Lefebvre, H. (1974). La producción del espacio. Papers: Revista de Sociología, 3.

Lefebvre, H. (1975). El derecho a la ciudad. 3. ${ }^{\text {a ed. }}$ Barcelona: Península. [1967].

Lefebvre, H. (1975b). Tiempos equívocos. Testimonio autobiográfico. Madrid: Kairos.

Lefebvre, H. (1976). Espacio y política. El derecho a la ciudad II. Barcelona: Península.

Lefebvre, H. (1978). La vida social en la ciudad. De lo urbano a lo rural. Barcelona: Península. [1971].

Lefebvre, H. (1978b). De lo urbano a lo rural. Conferencia en la ciudad universitaria de Antony (13 de noviembre de 1967). Barcelona: Península. [1971].

Lefebvre, H. (1989). Quand la ville se perd dans une métamorphose planétaire. Le monde diplomatique. Mayo.

Lefebvre, H. (2013). La producción del espacio. Madrid: Capitan Swing Libros. [1974].

Martin, J. (2007). Les origines d'une lecture marxiste lefebvrienne de la ville au Brésil. La Somme Et Le Reste, 9.
El derecho a la ciudad: de Henri Lefebvre a los análisis sobre la ciudad capitalista contemporánea Frank Molano Camargo

Merrifield, A. (2006). Henri Lefebvre: A critical Introduction. Nueva York: Routledge.

Merrifield, A. (2011-2012). El derecho a la ciudad y más allá: notas sobre una reconceptualización lefebvriana. Urban, 2.

Purcell, M. (2003). Citizenship and the right to the global city: Reimagining the capitalist world order. International Journal of Urban and Regional Research, $27,3$.

Revol-Buisson, C. (2012). Le succès de Lefebvre dans les urban studies anglo-saxonnes et les conditions de sa redécouverte en France. L'Homme et la société, 3, 185-186.

Soja, E. (1996). Third Space. Journeys to Los Angeles and Other Real-and-Imagined Places. Cambridge: Blackwell Publishers Inc.

Soja, E. (2008). Posmetrópolis, estudios críticos sobre las ciudades y las regiones. Madrid: Traficantes de Sueños. [2000].

Soja, E. (2013). Posmoderm geographies. The reassertion of space in critical social theory. Nueva York: Verso. [1989].

Soja, E. (2014). En busca de la justicia espacial. Valencia: Tirant Humanidades. [2010].

Santos, C. Celso \& Rossbach A. (2010). El estatuto de la ciudad: un comentario. São Paulo: Ministerio de las Ciudades, Alianza de las Ciudades.

Sugranyes, A. \& Mathivet, C. (Eds) (2010). Ciudades para tod@s. Por el derecho a la ciudad, propuestas y experiencias. Santiago de Chile: Habitat International Coalition. 